\title{
Curcumin inhibits angiotensin II-induced inflammation and proliferation of rat vascular smooth muscle cells by elevating PPAR- $\gamma$ activity and reducing oxidative stress
}

\author{
HAI-YU LI ${ }^{1}$, MEI YANG ${ }^{2}, \mathrm{ZE} \mathrm{LI}^{1}$ and ZHE MENG ${ }^{1}$ \\ ${ }^{1}$ Department of Cardiology, The First Affiliated Hospital of Zhengzhou University, Zhengzhou, Henan 450052; \\ ${ }^{2}$ Department of General Medicine, Renji Hospital of Shanghai Jiaotong University, Shanghai 200000, P.R. China
}

Received August 7, 2016; Accepted March 8, 2017

DOI: 10.3892/ijmm.2017.2924

\begin{abstract}
Angiotensin II (AngII)-induced production of inflammatory factors and proliferation in vascular smooth muscle cells (VSMCs) play an important role in the progression of atherosclerotic plaques. Growing evidence has demonstrated that activation of peroxisome proliferator-activated receptor- $\gamma$ (PPAR- $\gamma$ ) effectively attenuates AngII-induced inflammation and intercellular reactive oxygen species (iROS) production. Curcumin (Cur) inhibits inflammatory responses by enhancing PPAR- $\gamma$ activity and reducing oxidative stress in various tissues. The aim of the present study was to ascertain whether Cur inhibits AngII-induced inflammation and proliferation, and its underlying molecular mechanism, in VSMCs. Enzyme-linked immunosorbent assay (ELISA) and real-time PCR were used to measure the protein and mRNA expression of interleukin-6 (IL-6) and tumor necrosis factor- $\alpha$ (TNF- $\alpha$ ). Nitric oxide (NO) production was measured by Griess reaction. Western blot analysis and a DNA-binding assay were used to measure PPAR- $\gamma$ activity. iROS production was measured using the DCFH-DA method. In rat VSMCs, Cur attenuated AngII-induced expression of IL- 6 and TNF- $\alpha$ mRNA and protein in a concentration-dependent manner, inhibited NO production by suppressing inducible NO synthase (iNOS) activity, and suppressed proliferation of VSMCs. This was accompanied by increased PPAR- $\gamma$ expression and activation in Cur-pretreated VSMCs. GW9662, a PPAR- $\gamma$ antagonist, reversed the anti-inflammatory effect of Cur. Moreover, Cur attenuated AngII-induced oxidative stress by downregulating the expression of p47phox, which is a key subunit of nicotinamide adenine dinucleotide phosphate (NADPH) oxidase. In conclusion, Cur inhibited the expression of IL- 6 and TNF- $\alpha$, decreased the production of $\mathrm{NO}$, and suppressed the prolifera-
\end{abstract}

Correspondence to: Dr Zhe Meng, Department of Cardiology, The First Affiliated Hospital of Zhengzhou University, 1 East Jianshe Road, Zhengzhou, Henan 450052, P.R. China

E-mail: mengzhenihao@163.com

Key words: curcumin, angiotensin II, inflammation, peroxisome proliferator-activated receptor- $\gamma$, oxidative stress tion of VSMCs, by elevating PPAR- $\gamma$ activity and suppressing oxidative stress, leading to attenuated AngII-induced inflammatory responses in VSMCs.

\section{Introduction}

Changing life styles in China have contributed to a rise in atherosclerosis resulting in coronary heart disease (CHD), causing serious morbidity and mortality (1). Growing evidence has revealed that long-lasting and low-grade inflammation is a key cause of the progression of atherosclerosis $(2,3)$. The abnormal proliferation of vascular smooth muscle cells (VSMCs) and their expression of various pro-inflammatory cytokines such as interleukin-6 (IL-6) and tumor necrosis factor- $\alpha(\mathrm{TNF}-\alpha)$ play an important role in the process of inflammation within atherosclerotic plaques $(4,5)$. Angiotensin II (AngII), which is increased significantly in the serum of patients with acute coronary syndrome (ACS), may promote the process of atherosclerosis and plaque rupture by recruiting monocytes, activating macrophages, producing proinflammatory factors and causing oxidative stress $(6,7)$. More importantly, these pro-atherosclerotic effects of AngII do not depend on the elevation of systolic blood pressure.

Peroxisome proliferator-activated receptor- $\gamma$ (PPAR- $\gamma$ ), a member of the nuclear hormone family, plays a critical role in regulating glucose homeostasis and adipose metabolism. After activation, PPAR- $\gamma$ binds to specific PPAR response elements (PPREs) and then regulates the transcription of its target genes $(8,9)$. In recent years growing evidence has shown that the activity of PPAR- $\gamma$ may potentially downregulate inflammatory responses caused by various proinflammatory stimuli (10-12). Moreover, PPAR- $\gamma$ also participates in the production of AngII-induced proinflammatory factors by VSMCs, and thiazolidinediones (TZDs), synthetic PPAR- $\gamma$ agonists, may significantly inhibit this inflammatory effect (13). PPAR- $\gamma$ also plays an important role in regulating VSMC proliferation which can significantly affect the process of cardiac fibrosis (14).

Oxidative stress, characterized by the overproduction of intercellular reactive oxygen species (iROS), can trigger multiple pathological responses related to atherosclerosis, including oxidation of lipids and proteins, proliferation and 
migration of VSMCs, and overexpression of proinflammatory cytokines (15). Common risk factors for atherosclerosis such as hypertension, hypercholesterolemia, obesity and smoking may enhance the production of ROS in VSMCs. NADPH activation is the principle cause of ROS production by VSMCs (16). Previous studies have revealed that inhibition of the activation of NADPH reduced high-fat diet-induced increase in the area of atherosclerostic plaques in $\mathrm{ApoE}^{-/-}$mice $(17,18)$, compared with the control group.

Curcumin (Cur) is a natural polyphenol and is the principal curcuminoid present in Curcuma longa. Cur is responsible for the yellow color of turmeric and has been used in herbal remedies to treat inflammation- and infection-related diseases in China and India since ancient times (19). Cur has many pharmacological effects including anti-inflammatory, antioxidant, anti-microbial, anti-proliferative, neuroprotective and cardioprotective activities $(5,14,20,21)$. Recently, some studies have found that Cur attenuates the progression of atherosclerosis by inhibiting pro-inflammatory cytokine expression and ROS production, in vivo and in vitro $(5,22)$. Our previous study found that Cur inhibited LPS-induced inflammation through a TLR4mediated and ROS-relative signaling pathway in VSMCs (5). Furthermore, Cur attenuates cardiac fibrosis by elevating PPAR- $\gamma$ activation (14). However, the molecular mechanisms underlying the anti-inflammatory and anti-proliferative effects of Cur in AngII-stimulated VSMCs are not well known.

Therefore, our present study aimed to ascertain whether Cur can suppress AngII-induced expression of pro-inflammatory mediators and whether its cardioprotective effect is partially dependent on PPAR- $\gamma$ activity and a reduction in oxidative stress.

\section{Materials and methods}

Reagents. Dulbecco's modified Eagle's medium (DMEM) and fetal bovine serum (FBS) were provided by Gibco-BRL (Carlsbad, CA, USA). Curcumin (purity over 98\%), penicillin, streptomycin, Tris, EDTA, 2',7'-dichlorodihydrofluororescein diacetate (DCFH-DA), diphenyleneiodonium (DPI), 3-(4,5-dimethylthiazol-2-yl)-2,5-diphenyltetrazolium bromide (MTT), GW9662, and 2,2-diphenyl-1-picrylhydrazyl (DPPH) were purchased from Sigma Chemical Co. (St. Louis, MO, USA). The following primary antibodies were used: PPAR- $\gamma$ (GW21258-50UG; Sigma Chemical Co.), p47phox (4312S; Cell Signaling Technology., Inc., Danvers, MA, USA), inducible NO synthase (iNOS; xy-2977; Xin Yu Biotech Co., Shanghai, China) and histone (orb48770; Biorbyt Ltd., Cambridge, UK) . TranZol, TransStrat Green qPCR SuperMix, EasyScript Reverse Transcriptase and the $\beta$-actin antibody (VSC47778; www. biomart.cn) were purchased from TransGen Biotechnology (Beijing, China). IL-6 and TNF- $\alpha$ enzyme-linked immunosorbent assay (ELISA) kits were purchased from Thermo Fisher Scientific (Rockford, IL, USA).

VSMC culture. The present study was approved by the Ethics Committee of the Laboratory Animal Institute in the School of Medicine at Zhengzhou University, and carried out in strict accordance with the Guide for the Care and Use of Laboratory Animals published by the US National Institutes of Health (NIH publication no. 85-23, revised 1996). Male Sprague-Dawley rats (weighing 150-180 g) were purchased from the Laboratory
Animal Institute in the School of Medicine at Zhengzhou University. VSMCs were isolated from the thoracic aorta of rats, according to a previously described method (23). Cells were cultured in DMEM containing 20\% FBS, $100 \mathrm{U} / \mathrm{ml}$ penicillin and $100 \mu \mathrm{g} / \mathrm{ml}$ streptomycin in a humidified atmosphere of $5 \% \mathrm{CO}_{2}$ at $37^{\circ} \mathrm{C}$. Cells that were between passage 3 and 10 were used for all experiments. Cells at $80-90 \%$ confluence in culture dishes were growth-arrested by serum starvation for $16 \mathrm{~h}$.

Cell proliferation assay. Cells were planted at a density of 6,000 cells/well in 96-well plates. An MTT reduction assay and cell count experiments were used to determine the amount of cell proliferation. After the indicated treatments, the medium was removed and the cells were incubated with MTT $\left(5 \mathrm{mg} / \mathrm{ml}\right.$ ) for $4 \mathrm{~h}$ at $37^{\circ} \mathrm{C}$. The dark blue formazan crystals that formed in intact cells were solubilized with DMSO, and then the absorbance was measured at $490 \mathrm{~nm}$ on a microplate reader (Bio-Rad, Hercules, CA, USA). Cell count experiments were performed as previously described. Cells were counted by a hemocytometer using light microscopy.

Real-time reverse-transcriptase polymerase chain reaction. Total RNA was extracted by TransZol reagent (TransGen Biotechnology). The quality of total mRNA was measured by denaturing agarose gel electrophoresis containing $1.5 \%$ formaldehyde. Total RNA concentration and purity were determined using UV-Vis spectroscopy with the Bio-Rad SmartSpec 5000 system (Bio-Rad). cDNA was synthesized from $1 \mu \mathrm{g}$ of total RNA in a $20 \mu \mathrm{l}$ reaction using oligo(dT) primers and TransScript ${ }^{\mathrm{TM}}$ reverse transcriptase (TransGen Biotechnology). Primers for rat PPAR- $\gamma$, TNF- $\alpha$, IL-6, iNOS, p47phox and glyceraldehyde 3-phosphate dehydrogenase (GAPDH) were designed using Beacon designer v6.0 software (Premier Biosoft, Palo Alto, CA, USA) and are listed in Table I. GAPDH was used as an endogenous control. mRNA levels of PPAR- $\gamma$, TNF- $\alpha$, IL- 6 , iNOS and GAPDH were measured using real-time PCR on the ABI PRISM 7000 sequence detection PCR system (Applied Biosystems, Foster City, CA, USA). A melting point dissociation curve was used to confirm that only a single PCR product was obtained. Results were expressed as fold difference relative to the level of GAPDH by the $2^{-\Delta \Delta \mathrm{CT}}$ method.

Western blot analysis. Lysates of $\sim 6 \times 10^{6}$ VSMCs were prepared using $200 \mu \mathrm{l}$ ice-cold lysis buffer (pH 7.4) $(50 \mathrm{mmol} / \mathrm{l}$ HEPES, $5 \mathrm{mmol} / 1$ EDTA, $100 \mathrm{mmol} / 1 \mathrm{NaCl}, 1 \%$ Triton X-100, protease inhibitor cocktail; Roche, Mannheim, Germany) in the presence of phosphatase inhibitors $(50 \mathrm{mmol} / \mathrm{l}$ sodium fluoride, $1 \mathrm{mmol} / 1$ sodium orthovanadate, $10 \mathrm{mmol} / 1$ sodium pyrophosphate, $1 \mathrm{nmol} / 1$ microcystin). The nuclear PPAR- $\gamma$ protein was extracted using a Pierce NE-PER kit (Pierce, Rockford, IL, USA). The protein concentration was measured using a BCA protein assay kit. Samples underwent 10 or $12 \%$ sodium dodecyl sulfate-polyacrylamide gel electrophoresis (SDS-PAGE) and were transferred onto a polyvinylidene difluoride membrane in a semi-dry system, which was blocked with $5 \%$ fat-free milk in TBST buffer (20 mmol/l Tris-HCl, $137 \mathrm{mmol} / \mathrm{l} \mathrm{NaCl}$ and $0.1 \%$ Tween-20), and incubated with primary antibodies recognizing PPAR- $\gamma$ (1:400), iNOS (1:500), p47phox $(1: 400)$, histone $(1: 1,000)$, 
and $\beta$-actin $(1: 2,000)$, respectively, in TBST buffer overnight, washed and incubated with secondary antibodies for $90 \mathrm{~min}$. The optical density of the bands was scanned and quantified using a Gel-Pro Analyzer v4.0 (Media Cybernetics LP, Silver Spring, MD, USA). $\beta$-actin was used as an endogenous control. Data were normalized to $\beta$-actin levels.

Enzyme-linked immunoassay for cytokines and chemokines. VSMCs were cultured into 6-well plates at $5 \times 10^{6}$ cells/well and incubated with Cur (5, 10 and $20 \mu \mathrm{mol} / \mathrm{l})$ (14) with or without AngII $\left(10^{-7} \mathrm{~mol} / \mathrm{l}\right)$ for $24 \mathrm{~h}$. Cells were pretreated with the PPAR- $\gamma$ antagonist GW9662 $(10 \mu \mathrm{mol} / \mathrm{l})$ and the NADPH oxidase inhibitor DPI $(25 \mu \mathrm{mol} / \mathrm{l})$ for $1 \mathrm{~h}$, and then stimulated with AngII $\left(10^{-7} \mathrm{~mol} / \mathrm{l}\right)$ for another $24 \mathrm{~h}$. The amounts of TNF- $\alpha$ and IL- 6 in the supernatants were measured by ELISA according to the manufacturer's instructions.

Measurement of nitrite. The Griess reaction was used to determine the level of nitrite, a stable precursor of NO (24). Fifty microliters of the culture supernatant was mixed with an equal volume of Griess reagent $(0.1 \%$ naphthyl-ethylenediamine, $1 \%$ sulfanylamide and $2.5 \%$ phosphoric acid). Absorbance was measured on a microplate reader at $540 \mathrm{~nm}$, using a calibration curve with sodium nitrite standards.

Intracellular ROS assay. The level of intracellular ROS was measured using the DCFH-DA method, based on the ROS-dependent oxidation of DCFH to the highly fluorescent DCF. DCFH was dissolved in methanol at $10 \mathrm{mmol} / \mathrm{l}$ and then diluted by a factor of 500 in Hank's balanced salt solution (HBSS) to give a final DCFH concentration of $20 \mu \mathrm{mol} / 1$. The cells were incubated with DCFH-DA for $1 \mathrm{~h}$ and then treated with HBSS containing Cur $(5,10$ or $20 \mu \mathrm{mol} / \mathrm{l})$ or AngII $\left(10^{-7} \mathrm{~mol} / \mathrm{l}\right)$ for another $100 \mathrm{~min}$. The fluorescence was immediately measured using $485 \mathrm{~nm}$ for excitation and $528 \mathrm{~nm}$ for emission on the $\mathrm{iMark}^{\mathrm{TM}}$ microplate absorbance reader (Bio-Rad).

Stable free radical scavenging activity. Stable free radical scavenging activity was detected using the method reported by Jeong et al (25). Briefly, $100 \mu \mathrm{mol} / 1$ of DPPH radical solution was dissolved in $100 \%$ ethanol. The mixture was shaken vigorously and allowed to stand for $10 \mathrm{~min}$ in the dark. The test materials (100 $\mu \mathrm{l}$ each) were added to $900 \mu \mathrm{l}$ of the DPPH radical solution. After incubation at room temperature for $30 \mathrm{~min}$, the absorbance at $517 \mathrm{~nm}$ was measured using the SPECTRA (shell) reader.

Statistical analysis. The significance between groups was analyzed using ANOVA, and the difference between each of the 2 groups was detected using the post hoc test using 'Statistic version 8.0' (Statsoft Inc., Tulsa, OK, USA) software. Data are presented as mean \pm standard deviation (SD). A value of $\mathrm{P}<0.05$ was considered to be statistically significant.

\section{Results}

Cur inhibits IL-6 and TNF- $\alpha$ expression in AngII-stimulated VSCMs. VSMCs express a number of pro-inflammatory cytokines in response to different stimuli, which can dramati-
Table I. Primers used for real-time PCR analysis.

\begin{tabular}{ll}
\hline Gene & Oligonucleotide primer sequences (5'-3') \\
\hline IL-6 & F: GAGAAAAGAGTTGTGCAATGGC \\
& R: ACTAGGTTTGCCGAGTAGACC \\
TNF- $\alpha$ & F: TCCCAACAAGGAGGAGAAGT \\
& R: TGGTATGAAGTGGCAAATCG \\
p47phox & F: GAGACATACCTGACGGCCAAAGA \\
& R: AGTCAGCGATGGCCCGATAG \\
iNOS & F: CCACGCTCTTCTGTCTACTGAAC \\
& R: ACGGGCTTGTCACTCGAG \\
GADPH & F: ATCGGCAATGAGCGGTTCC \\
& R: AGCACTGTGTTGGCATAGAGG \\
\hline
\end{tabular}

F, forward; R, reverse; IL-6, interleukin- 6 ; TNF- $\alpha$, tumor necrosis factor- $\alpha$; iNOS, inducible nitric oxide synthase; GADPH, glyceraldehyde 3-phosphate dehydrogenase.

cally promote the progression of atherosclerotic plaques. As shown in Fig. 1, stimulation of VSMCs with AngII $\left(10^{-7} \mathrm{~mol} / \mathrm{l}\right)$ for $24 \mathrm{~h}$ caused a significant increase in the production of IL- 6 and TNF- $\alpha$. However, pretreatment with Cur attenuated AngII-induced production of IL- 6 and TNF- $\alpha$ in a concentration-dependent manner (Fig. 1A and B). Moreover, Cur also dose-dependently decreased the mRNA expression of IL-6 and TNF- $\alpha$ in AngII-stimulated VSMCs (Fig. 1C and D). Treatment with Cur $(20 \mu \mathrm{mol} / \mathrm{l})$ did not affect the expression of IL-6 and TNF- $\alpha$ (Fig. 1).

Cur attenuates AngII-induced NO production and iNOS expression. Cur markedly attenuated AngII-induced NO production in a concentration-dependent manner, but did not change NO production in the absence of AngII stimulation (Fig. 2A). Furthermore, AngII significantly increased the protein and mRNA expression of iNOS in VSMCs, which was concentration-dependently attenuated by Cur. Treating VSMCs with only Cur had no affect on the expression of iNOS mRNA and protein (Fig. 2B and C). These results indicated that Cur attenuated AngII-induced NO production in VSMCs, which was partly due to inhibition of iNOS activity.

Cur inhibits AngII-induced proliferation of VSMCs. As shown in Fig. 3, treating VSMCs with AngII $\left(10^{-7} \mathrm{~mol} / \mathrm{l}\right)$ for $24 \mathrm{~h}$ significantly increased their proliferation, while pretreating the cells with Cur $(5,10$ and $20 \mu \mathrm{mol} / \mathrm{l})$ suppressed this effect. However, treatment with Cur $(20 \mu \mathrm{mol} / \mathrm{l})$ alone did not affect the proliferation of VSMCs (Fig. 3).

Cur reduces AngII-induced free radical production in VSMCs. The free radical scavenging activity of Cur in AngII-stimulated VSMCs was measured using the DPPH reduction assay. Cur concentration-dependently scavenged the DPPH free radical caused by ROS in the AngII-stimulated VSMCs (Fig. 4). The results indicated that Cur exhibited free radical scavenging activity in the AngII-stimulated VSMCs. 

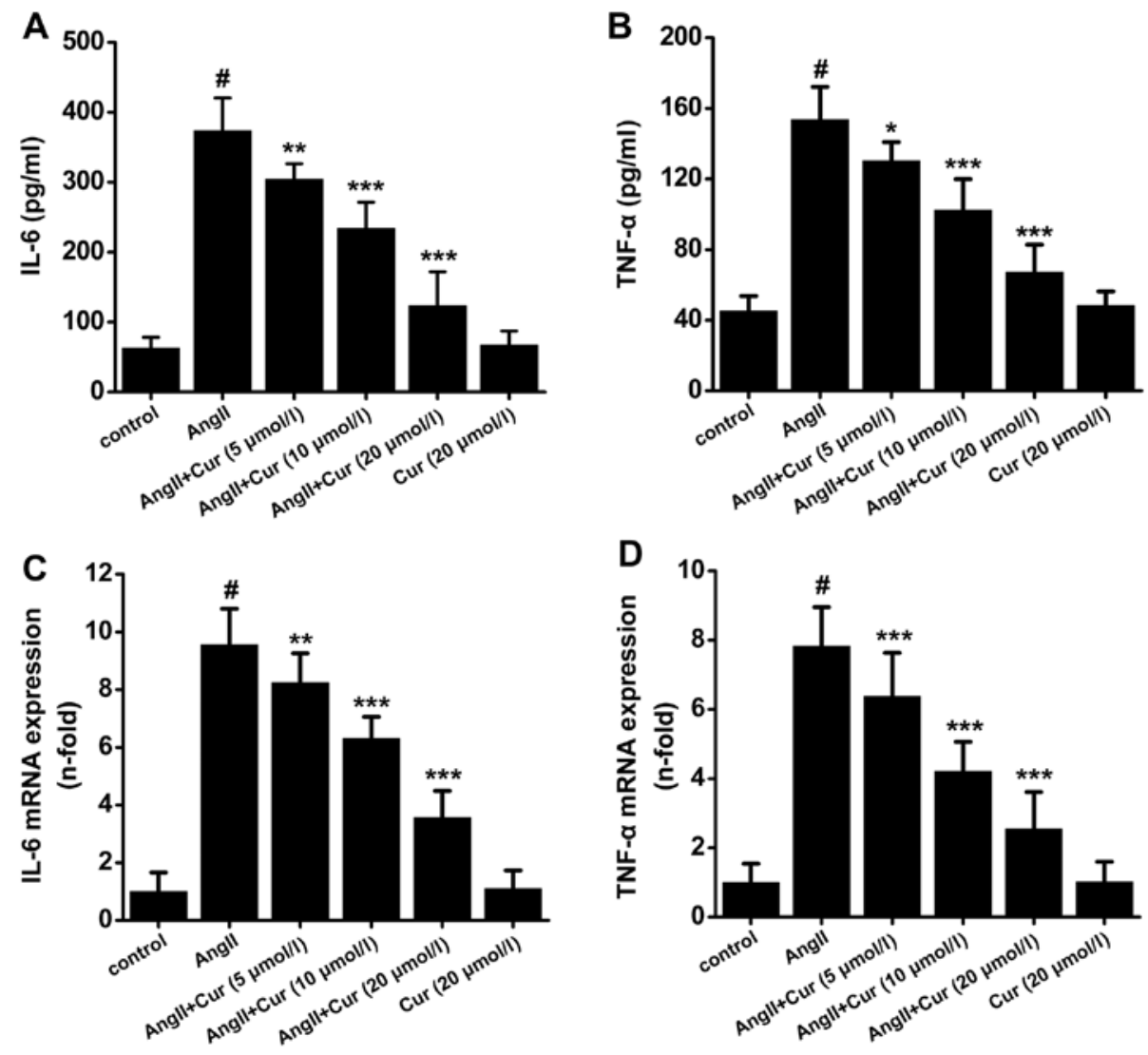

Figure 1. Inhibitory effect of curcumin (Cur) on angiotensin II (AngII)-induced expression of interleukin-6 (IL-6) and tumor necrosis factor- $\alpha$ (TNF- $\alpha$ ) in vascular smooth muscle cells (VSMCs). VSMCs were pretreated with the indicated concentrations of Cur $(5,10$ and $20 \mu \mathrm{mol} / 1)$ for $1 \mathrm{~h}$, and then stimulated with AngII $\left(10^{-7} \mathrm{~mol} / \mathrm{l}\right)$ for another $24 \mathrm{~h}$. Some cells were treated with Cur $(20 \mu \mathrm{mol} / \mathrm{l})$ alone for $24 \mathrm{~h}$. The culture medium was collected and the levels of (A) IL-6 and (B) TNF- $\alpha$ were measured with commercial enzyme-linked immunosorbent assay (ELISA) kits. Total RNA was abstracted after the same treatment for $6 \mathrm{~h}$, the levels of (C) IL- 6 and (D) TNF- $\alpha$ mRNAs were detected by quantitative real-time PCR. Data are presented as mean \pm SEM of six independent experiments. ${ }^{\#} \mathrm{P}<0.001$ vs. control; ${ }^{* * *} \mathrm{P}<0.001$ and ${ }^{* * *} \mathrm{P}<0.01$ vs. AngII.
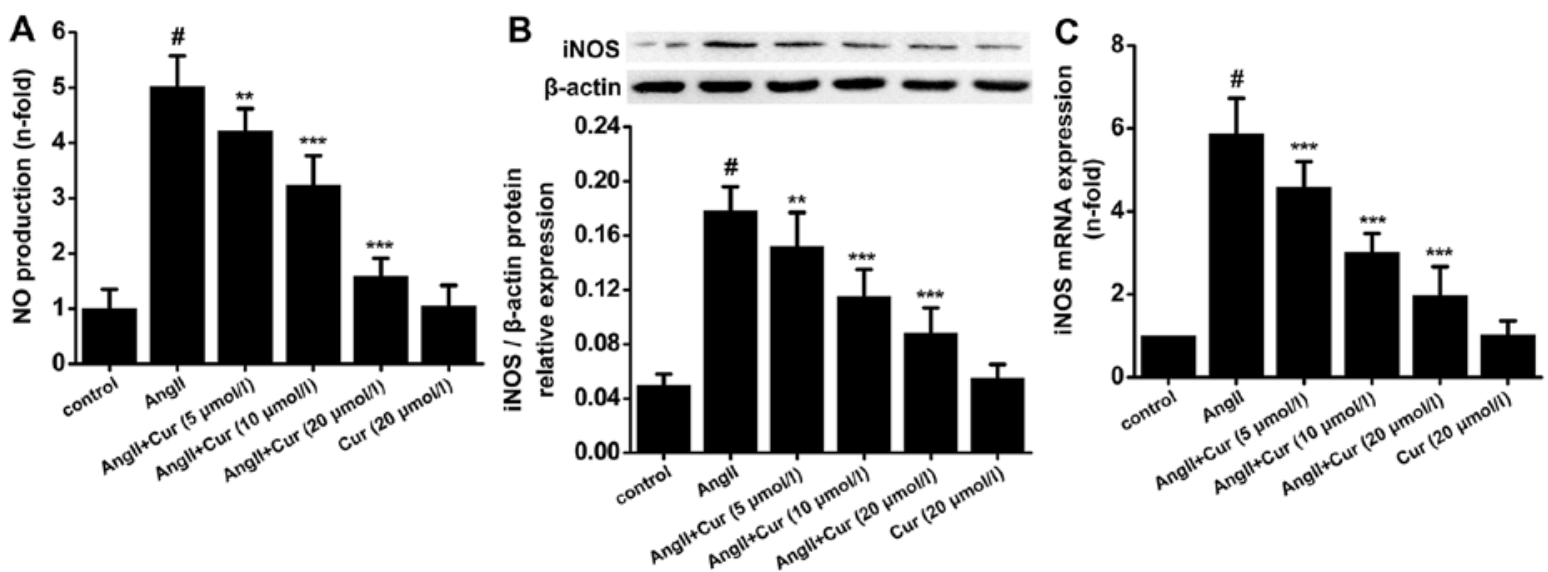

Figure 2. Inhibitory effect of curcumin (Cur) on angiotensin II (AngII)-induced nitric oxide (NO) production and inducible NO synthase (iNOS) expression in vascular smooth muscle cells (VSMCs). VSMCs were pretreated with the indicated concentrations of Cur (5,10 and $20 \mu \mathrm{mol} / 1)$ for $1 \mathrm{~h}$, and then stimulated with AngII $\left(10^{-7} \mathrm{~mol} / \mathrm{l}\right)$ for another $24 \mathrm{~h}$. Some cells were treated with Cur $(20 \mu \mathrm{mol} / \mathrm{l})$ alone for $24 \mathrm{~h}$. (A) The cell supernatants were collected to measure the NO production. VSMCs were pretreated with the indicated concentrations of Cur $(5,10$ and $20 \mu \mathrm{mol} / \mathrm{l})$ for $1 \mathrm{~h}$, and then stimulated with AngII $\left(10^{-7} \mathrm{~mol} / \mathrm{l}\right)$ for another 6 or $24 \mathrm{~h}$. Some cells were treated with Cur $(20 \mu \mathrm{mol} / 1)$ alone for $6 \mathrm{~h}$ or $24 \mathrm{~h}$. The levels of protein (B) and mRNA (C) of iNOS were respectively analyzed by western blot analysis after normalization to $\beta$-actin, and quantitative real-time PCR, in which glyceraldehyde 3-phosphate dehydrogenase (GAPDH) was used as an internal control. Data are presented as mean \pm SEM of six independent experiments. ${ }^{*} \mathrm{P}<0.001$ vs. control; ${ }^{* * * *} \mathrm{P}<0.001$ and ${ }^{* * *} \mathrm{P}<0.01$ vs. AngII.

Cur elevates the expression and activity of PPAR- $\gamma$ in AngII-stimulated VSMCs. To evaluate the expression and translocation of PPAR- $\gamma$ into the nucleus, nuclear protein was extracted and analyzed by western blot analysis and DNA-binding assay. As shown in Fig. 4, treating the cells with AngII $\left(10^{-7} \mathrm{~mol} / \mathrm{l}\right)$ for $24 \mathrm{~h}$ markedly decreased the expression 

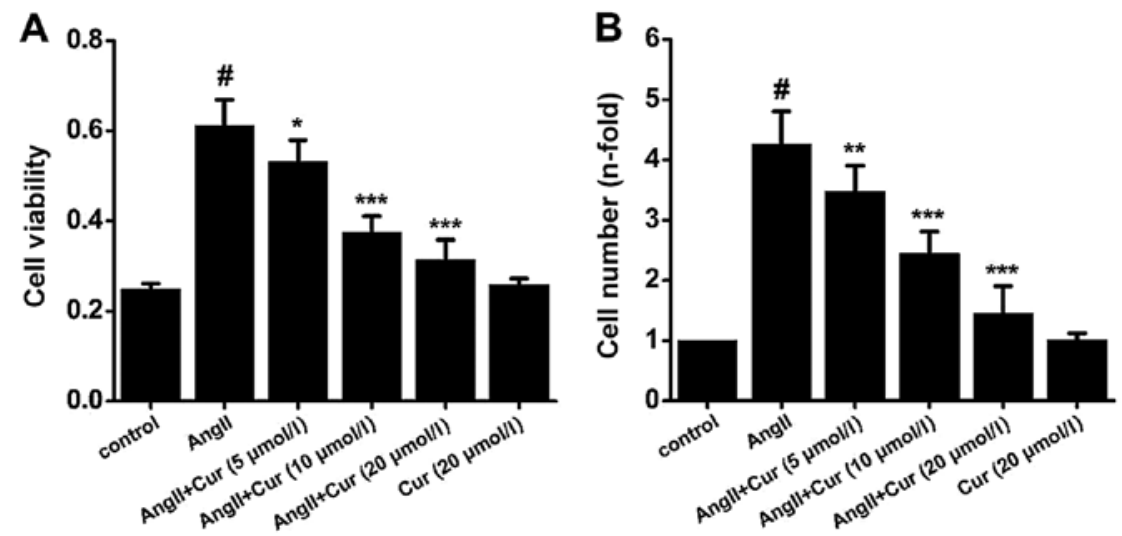

Figure 3. Curcumin (Cur) inhibits angiotensin II (AngII)-induced vascular smooth muscle cell (VSMC) proliferation. VSMCs were pretreated with the indicated concentrations of Cur $(5,10$ and $20 \mu \mathrm{mol} / \mathrm{l})$ for $1 \mathrm{~h}$, and then stimulated with AngII $\left(10^{-7} \mathrm{~mol} / \mathrm{l}\right)$ for another $24 \mathrm{~h}$. Some cells were treated with Cur $(20 \mu \mathrm{mol} / \mathrm{l})$ alone for $24 \mathrm{~h}$. MTT assay (A) and cell counting (B) were used to measure VSMC proliferation. Data are presented as mean \pm SEM of six independent experiments. ${ }^{\#} \mathrm{P}<0.001$ vs. control; ${ }^{* * *} \mathrm{P}<0.001$ and ${ }^{* *} \mathrm{P}<0.01$ vs. AngII.

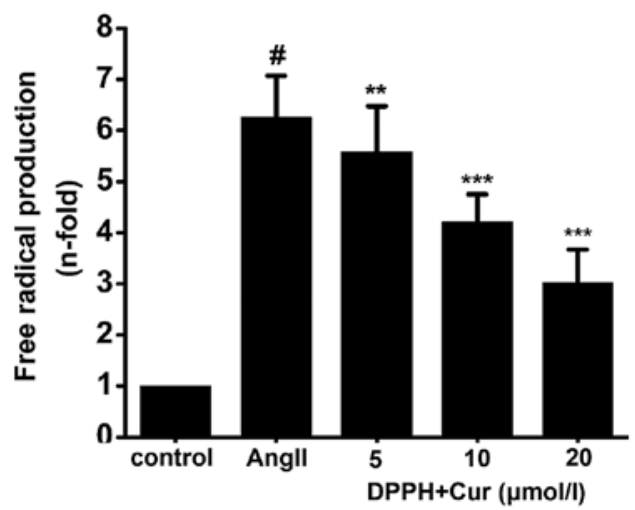

Figure 4. Inhibitory effect of curcumin (Cur) on angiotensin II (AngII)induced free radical scavenging activity in vascular smooth muscle cells (VSMCs). 2,2-Diphenyl-1-picrylhydrazyl (DPPH) at the concentration of $100 \mu \mathrm{mol} / 1$ was soluted in $100 \%$ ethanol, and then incubated alone or with Cur $(5,10$ and $20 \mu \mathrm{mol} / \mathrm{l})$ for $30 \mathrm{~min}$ at the room temperature. The absorbance at $517 \mathrm{~nm}$ was measured using the SPECTRA (shell) reader. Data are presented as mean \pm SEM of six independent experiments. ${ }^{\text {"}} \mathrm{P}<0.001$ vs. control; ${ }^{* * *} \mathrm{P}<0.001$ and ${ }^{* *} \mathrm{P}<0.01$ vs. AngII.

of PPAR- $\gamma$ in the nucleus and blocked its ability to bind the DNA response element PPRE. However, pretreating the cells with Cur significantly increased both PPAR- $\gamma$ translocation and bound PPRE in a concentration manner, compared with the AngII-treated cells (Fig. 5). Moreover, exposure to Cur (20 $\mu \mathrm{mol} / \mathrm{l})$ alone for $24 \mathrm{~h}$ caused an increase in the nuclear expression and activity of PPAR- $\gamma$ in the VSMCs, compared with the control cells (Fig. 5). These results indicated that Cur may be a potential promoter of PPAR- $\gamma$ activity in AngIIstimulated VSMCs.

Relationship between PPAR- $\gamma$ and the anti-inflammatory and anti-proliferative effect of Cur in VSMCs. To evaluate whether the anti-inflammatory and anti-proliferative effects of Cur are dependent upon PPAR- $\gamma$, VSMCs were pretreated with GW9662 (10 $\mu \mathrm{mol} / \mathrm{l})$, an antagonist of PPAR- $\gamma$, for $1 \mathrm{~h}$, treated with Cur $(20 \mu \mathrm{mol} / \mathrm{l})$ for $1 \mathrm{~h}$, and then exposed to AngII $\left(10^{-7} \mathrm{~mol} / \mathrm{l}\right)$ for another $24 \mathrm{~h}$. As shown in Fig. 6, compared with the control cells, AngII significantly increased the production of IL-6, TNF- $\alpha$ and NO (Fig. 6A-C), but this was significantly attenuated by Cur treatment. The PPAR- $\gamma$ antagonist GW9662 significantly reversed the inhibitory effect of Cur on the AngII-induced inflammation in VSMCs (Fig. 6A-C). As shown in Fig. 6, Cur significantly inhibited AngII-induced proliferation of VSMCs, which was reversed by pretreatment with GW9662 (Fig. 6D and E). The results suggest that the activation of PPAR- $\gamma$ plays a key role in Cur-mediated suppression of inflammatory factor production. However, compared with AngII and Cur, pretreating the cells with GW9662 to inhibit the activity of PPAR- $\gamma$ did not completely suppress the anti-inflammatory and antiproliferative effects of Cur in AngII-stimulated VSMCs, which suggests that other PPAR- $\gamma$-independent molecular mechanisms may partially contribute to these effects.

Cur suppresses AngII-induced iROS production and p47phox expression in VSMCs. The increase in iROS during inflammation causes various pathological responses such as the expression of pro-inflammatory cytokines, proliferation of VSMCs, and oxidation of lipids, which promotes the progression of atherosclerosis. According to our data, treating VSMCs with AngII $\left(10^{-7} \mathrm{~mol} / \mathrm{l}\right)$ for $24 \mathrm{~h}$ significantly increased iROS production, and pretreatment with Cur concentration-dependently attenuated this effect (Fig. 7A). p47phox is an important component of NAPDH oxidase which is the main source of iROS production in VSMCs. As shown in Fig. 7, Cur concentration-dependently suppressed AngII-induced expression of p47phox mRNA and protein (Fig. 7B and C).

Relationship between oxidative stress and the anti-inflammatory and anti-proliferative effects of Cur on VSMCs. To evaluate whether the increase in iROS was related to the antiinflammatory and anti-proliferative effect of Cur in VSMCs, cells were pretreated with or without DPI $(25 \mu \mathrm{mol} / \mathrm{l})$, an antagonist of NADPH oxidase, for $1 \mathrm{~h}$ before treatment with Cur $(20 \mu \mathrm{mol} / \mathrm{l})$ for $1 \mathrm{~h}$, and then incubated with AngII $\left(10^{-7} \mathrm{~mol} / \mathrm{l}\right)$ for $24 \mathrm{~h}$. Our data indicated that Cur and DPI both partially inhibited AngII-induced expression of IL-6 (Fig. 8A), TNF- $\alpha$ (Fig. 8B) and NO (Fig. 8C) in VSMCs. Pretreatment 

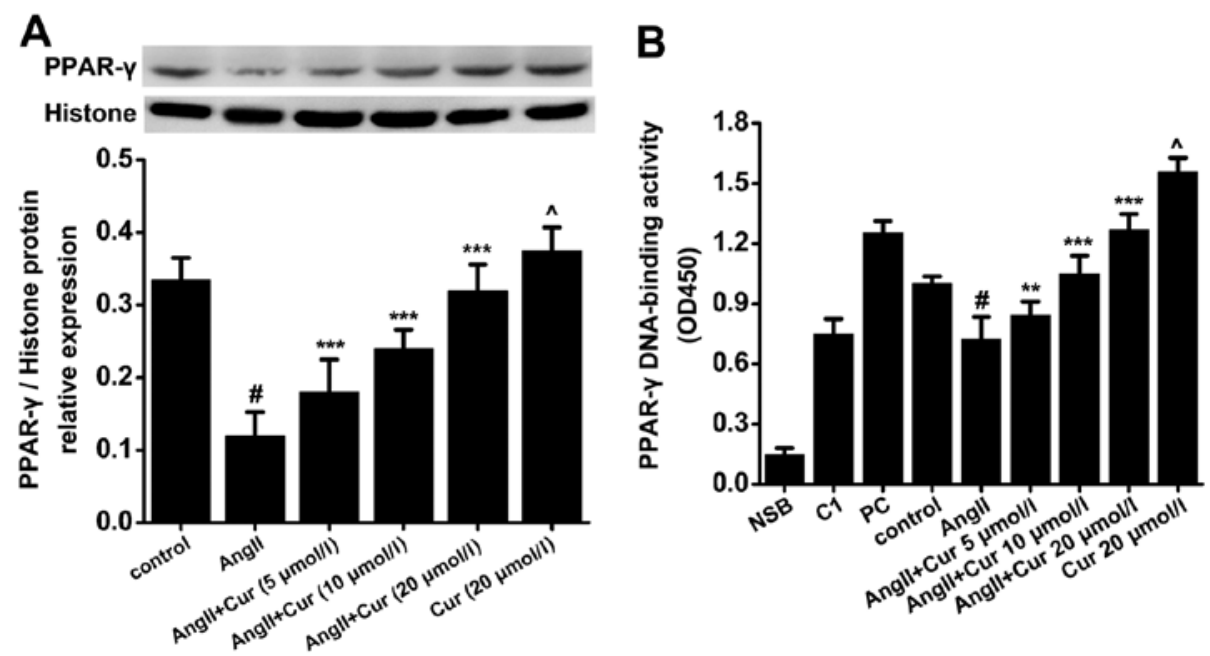

Figure 5. Curcumin (Cur) elevates the expression and activity of peroxisome proliferator-activated receptor- $\gamma$ (PPAR- $\gamma$ ) in angiotensin II (AngII)-stimulated vascular smooth muscle cells (VSMCs). VSMCs were pretreated with the indicated concentrations of Cur (5, 10 and $20 \mu$ mol/l) for $1 \mathrm{~h}$, and then stimulated with AngII $\left(10^{-7} \mathrm{~mol} / \mathrm{l}\right)$ for another $24 \mathrm{~h}$. Some cells were treated with Cur $(20 \mu \mathrm{mol} / \mathrm{l})$ alone for $24 \mathrm{~h}$. (A) The nuclear protein was abstracted and then western blot analysis was used to measure the expression of PPAR- $\gamma$, in which histone was used as an internal control. (B) The activity of PPAR- $\gamma$ was measured by the DNA-binding assay. Data are presented as mean \pm SEM of six independent experiments. ${ }^{*} \mathrm{P}<0.001$ vs. control; ${ }^{* * * *} \mathrm{P}<0.001$ and ${ }^{* * *} \mathrm{P}<0.01 \mathrm{vs}$. AngII.

A

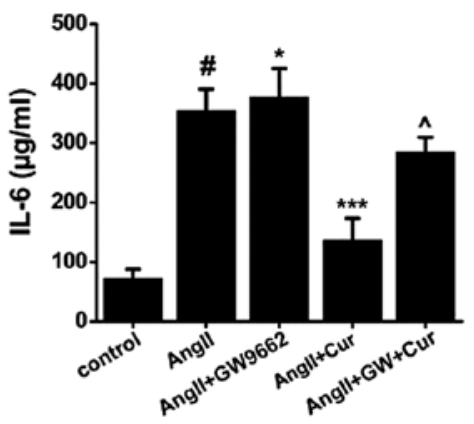

B

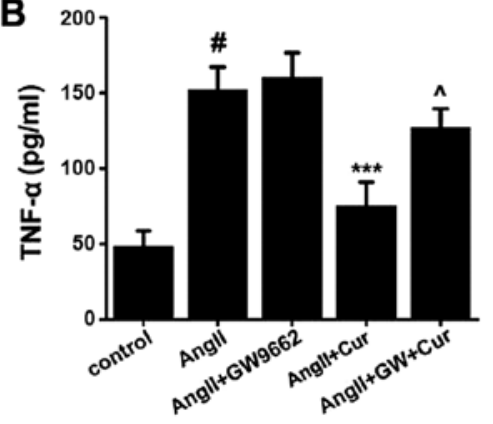

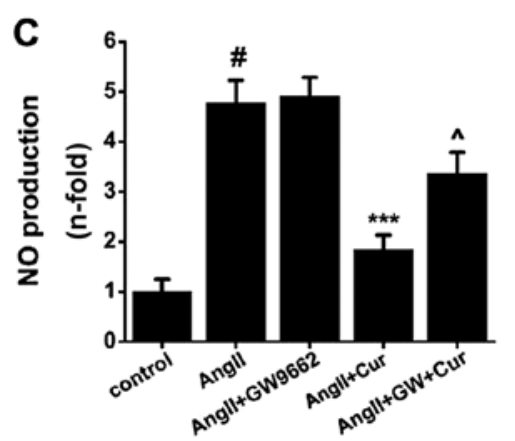
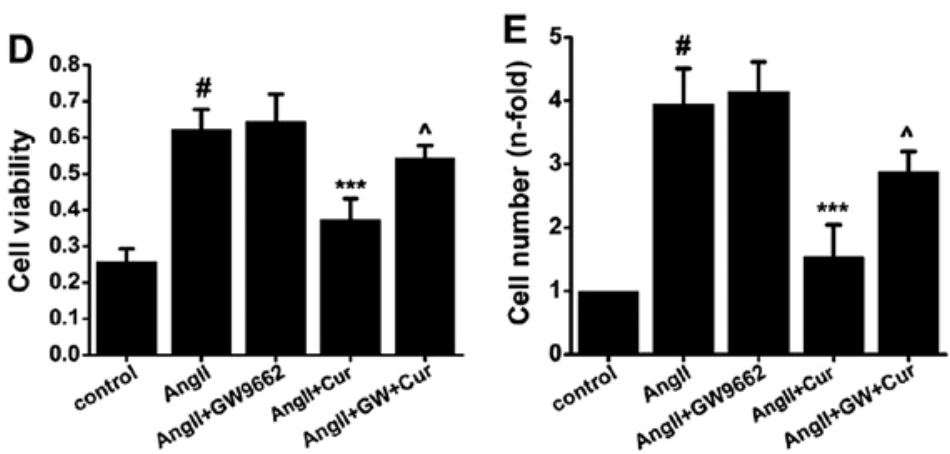

Figure 6. Activation of peroxisome proliferator-activated receptor- $\gamma($ PPAR- $\gamma)$ partially contributes to the anti-inflammatory and anti-fibrotic effect of curcumin (Cur). Vascular smooth muscle cells (VSMCs) were pretreated with PPAR- $\gamma$ antagonist GW9662 (10 $\mu \mathrm{mol} / 1)$, Cur (20 $\mu \mathrm{mol} / 1)$, or GW9662 (10 $\mu \mathrm{mol} / \mathrm{l})$ $+\operatorname{Cur}(20 \mu \mathrm{mol} / \mathrm{l})$ for $1 \mathrm{~h}$, and then stimulated with angiotensin II (AngII) $\left(10^{-7} \mathrm{~mol} / \mathrm{l}\right)$ for another $24 \mathrm{~h}$. The expression of interleukin-6 (IL-6) (A) and tumor necrosis factor- $\alpha(\mathrm{TNF}-\alpha)(\mathrm{B})$ was measured by enzyme-linked immunosorbent assay (ELISA) assay. Nitric oxide (NO) production was detected by Griess assay (C). The proliferation of VSMCs was measured by MTT (D) assay and cell counting (E). Data are presented as mean \pm SEM of three independent experiments. ${ }^{*} \mathrm{P}<0.001$ vs. control; ${ }^{* * *} \mathrm{P}<0.001$ and ${ }^{*} \mathrm{P}<0.05$ vs. AngII; ${ }^{\wedge} \mathrm{P}<0.001$ vs. AngII+Cur.

with a combination of Cur and DPI synergistically inhibited AngII-induced inflammation in VSMCs. Proliferation of VSMCs was also decreased when the cells were pretreated with Cur and DPI (Fig. 8D and E). These results suggest that Cur inhibits AngII-induced inflammation and proliferation in VSMCs partly through suppressing NADPH oxidase-mediated iROS.

\section{Discussion}

In the present study, we observed that Cur concentration-dependently suppressed AngII-induced production of TNF- $\alpha$, IL- 6 and NO and inhibited the proliferation of VSMCs in vitro. Our results indicated that the inhibitory effect of Cur on AngII-induced inflammation and proliferation of 

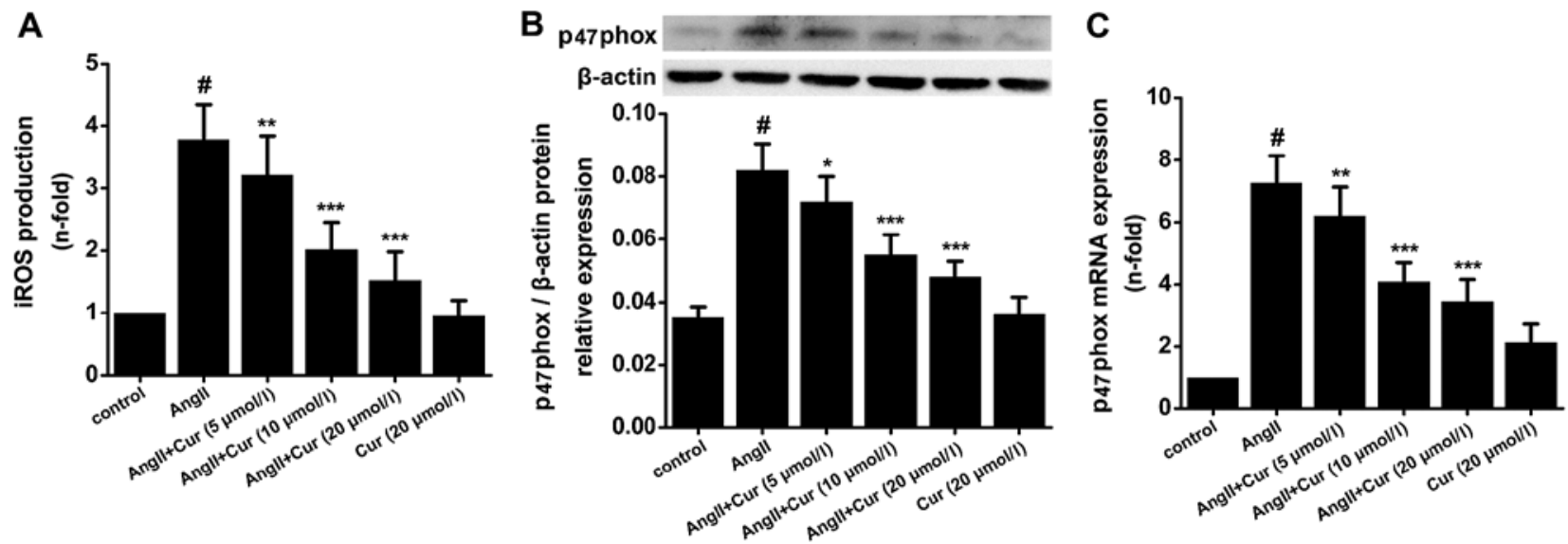

Figure 7. Curcumin (Cur) suppresses angiotensin II (AngII)-induced iROS production and p47phox expression in vascular smooth muscle cells (VSMCs). VSMCs were pretreated with the indicated concentrations of Cur $(5,10$ and $20 \mu \mathrm{mol} / \mathrm{l})$ for $1 \mathrm{~h}$, and then stimulated with AngII (10 ${ }^{-7}$ mol/1) for another 30 min. Some cells were treated with Cur $(20 \mu \mathrm{mol} / 1)$ alone for $30 \mathrm{~min}$. (A) The iROS production was detected by DCFH-DA method. The protein (B) and mRNA (C) expression of p47phox were respectively measured by western blot analysis and real-time PCR. Data are presented as mean \pm SEM of three independent experiments. ${ }^{*} \mathrm{P}<0.001$ vs. control; ${ }^{* * *} \mathrm{P}<0.001,{ }^{* *} \mathrm{P}<0.01$ and ${ }^{*} \mathrm{P}<0.05$ vs. AngII.
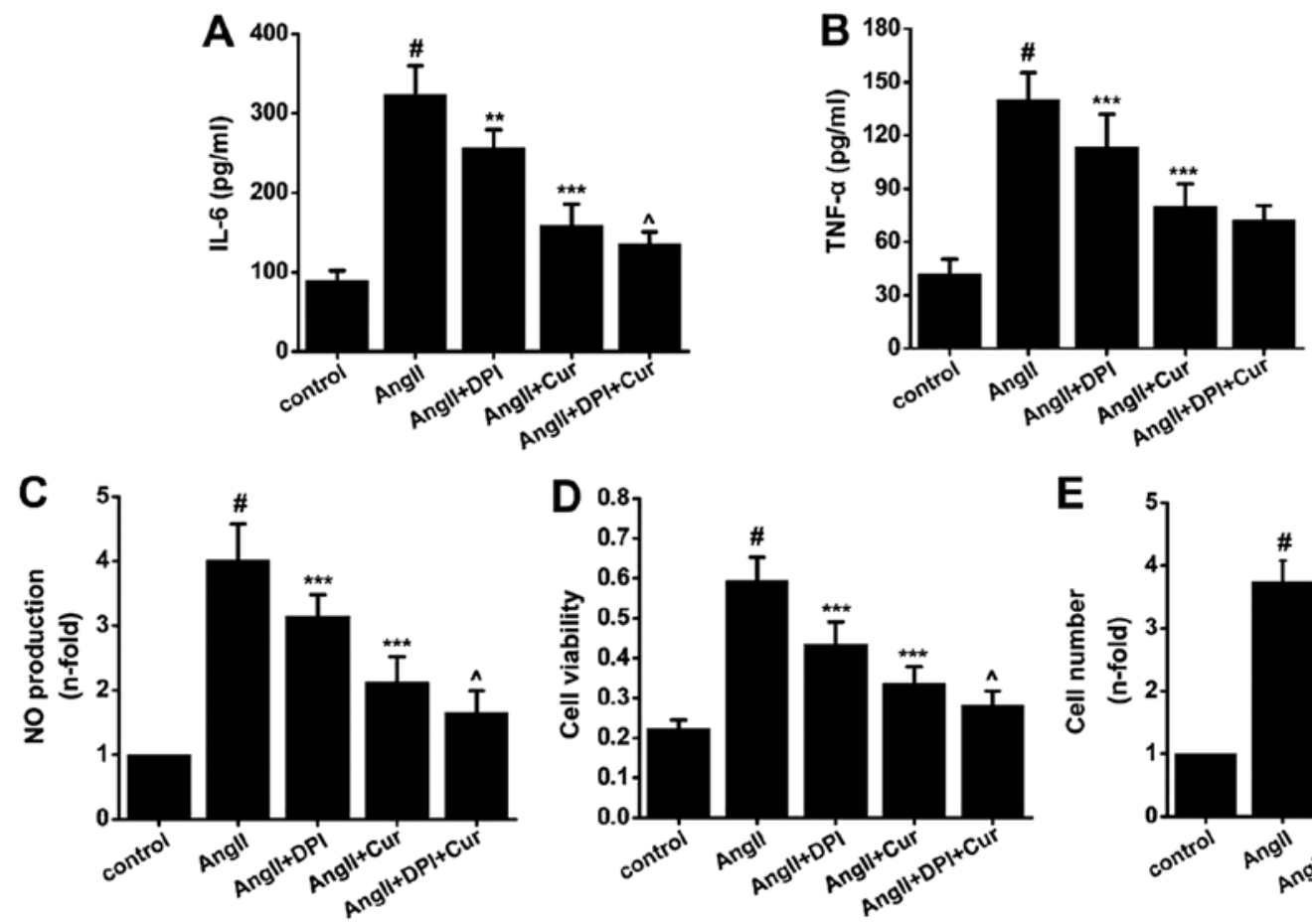

Figure 8. Relationship between oxidative stress and the anti-inflammatory and anti-proliferative effect of curcumin (Cur) in vascular smooth muscle cells (VSMCs). VSMCs were pretreated with peroxisome proliferator-activated receptor- $\gamma$ (PPAR- $\gamma$ ) antagonist DPI $(25 \mu \mathrm{mol} / 1)$, Cur $(20 \mu \mathrm{mol} / 1)$, or DPI $(25 \mu \mathrm{mol} / \mathrm{l})+\operatorname{Cur}(20 \mu \mathrm{mol} / \mathrm{l})$ for $1 \mathrm{~h}$, and then stimulated with angiotensin II (AngII) $\left(10^{-7} \mathrm{~mol} / \mathrm{l}\right)$ for another $24 \mathrm{~h}$. The expression of interleukin-6 (IL-6) (A) and tumor necrosis factor- $\alpha$ (TNF- $\alpha$ ) (B) was measured by enzyme-linked immunosorbent assay (ELISA) assay. Nitric oxide (NO) production was detected by Griess assay (C). The proliferation of VSMCs was measured by MTT assay (D) and cell counting (E). Data are presented as mean \pm SEM of three independent experiments. ${ }^{"} \mathrm{P}<0.001$ vs. control; ${ }^{* * *} \mathrm{P}<0.001$ and ${ }^{* *} \mathrm{P}<0.05$ vs. AngII; ${ }^{\wedge} \mathrm{P}<0.001$ vs. AngII+Cur.

VSMCs was partly dependent on enhancing PPAR- $\gamma$ activity and reducing NADPH-mediated iROS production. These findings show a novel relationship between the anti-inflammatory and anti-proliferative effect of Cur and PPAR- $\gamma$ activation and oxidative response in AngII-induced VSMCs, which enables a better understanding of the molecular mechanisms of the beneficial effect of Cur on atherosclerosis.

Although atherosclerosis is regarded as a complex pathological disease, the long-lasting and low-grade inflammatory response within the arterial walls is a critical factor that enhances the progression of atherosclerosis and plaque instability (3). IL-6, which is elevated in the serum of patients with ACS, is a potential pro-inflammatory factor as it increases the release of fibrinogen and promotes platelet aggregation (26). TNF- $\alpha$ enhances the progression of atherosclerosis and this process depends upon the induction of endothelium dysfunction, inflammatory cytokine production, and the increased apoptosis of VSMCs (26). AngII promotes inflammatory 
responses and oxidative stress of various cell types such as endothelium, VSMCs, and macrophages, within atherosclerotic plaques (27,28). AngII upregulates the expression of various pro-inflammatory mediators in VSMCs including TNF- $\alpha$, MCP-1, IL-6 and nitric oxide synthase (29). In our previous study, we demonstrated that Cur significantly suppressed LPS-induced expression of TNF- $\alpha$ and MCP-1, two mediators that also play an important role in the progression of inflammatory responses within atherosclerotic plaques by inducing macrophage chemotaxis and cell apoptosis in VSMCs (5). Therefore, we postulated that Cur may inhibit AngII-induced inflammation in VSMCs. Our data showed that Cur significantly decreased AngII-induced production of TNF- $\alpha$ and IL-6, and the anti-inflammatory effect of Cur was concentration-dependent. Previous studies have shown that Cur also suppressed ox-LDL, TNF- $\alpha$ and PMA-induced inflammation in different cell types, which indicates that the anti-inflammatory effect of Cur is multifaceted and not only dependent upon AngII.

The production of NO in endothelial cells by the enzyme ecNOS is beneficial for attenuating AngII-induced dysfunction in endothelial cells in the initial formation of atherosclerotic plaques (30). However, high concentrations of NO promote the progression of atherosclerosis by enhancing intercellular ROS production and causing significant endothelial cell dysfunction. High amounts of NO react with superoxide to become peroxynitrite, causing oxidative stress and then increasing intercellular ROS (31). Moreover, deficiency in iNOS is accompanied by a decrease in NO production reducing atherosclerosis in apolipoprotein E-deficient mice (32). These studies indicate that suppressing the production of NO by iNOS may be a possible way to delay the progression of atherosclerosis. Additionally, in our previous study, we found that Cur can inhibit LPS-induced activity of iNOS and then suppress production of NO in VSMCs (5). In our present experiments, we observed that Cur suppressed AngII-induced NO production, accompanied by a decrease in the expression of iNOS (both protein and mRNA) in VSMCs. These results suggest that Cur can significantly inhibit AngII-induced NO production by suppressing the activity of iNOS in VSMCs, providing a new molecular mechanism for the anti-inflammatory and anti-atherosclerotic effect of Cur.

Although PPAR- $\gamma$ was initially thought to regulate the metabolism of glucose and lipid, it also participates in controlling various physiological functions, especially inflammation and proliferation (33). Previous studies have shown that AngII can inhibit PPAR- $\gamma$ activity, which accelerates the progression of atherosclerosis and increases plaque instability by upregulating the production of numerous types of proinflammatory factors production (12). After treatment with AngII, the concentration of MCP-1, VCAM-1 and ICAM-1 were significantly increased in apolipoprotein E-deficient mice (34). Moreover, some PPAR- $\gamma$ agonists such as rosiglitazone and telmisartan can suppress AngII-induced inflammation in vivo and in vitro $(13,35)$. These studies suggest that increasing PPAR- $\gamma$ activity inhibits AngII-induced production of proinflammatory factors, providing an effective method to delay the progression of atherosclerosis and enhance plaque stability. Additionally, Cur is a potential PPAR- $\gamma$ agonist. Siddiqui et al reported that by upregulating PPAR- $\gamma$, Cur inhibited inflammation in an experimental model of sepsis (36). Cur also suppressed the expression of TNF- $\alpha$ and ameliorated renal failure by activating PPAR $-\gamma$ in 5/6 nephrectomized rats (37). In the liver, Cur increased PPAR $-\gamma$ activity and attenuated oxidative stress and suppressed inflammation in $\mathrm{CCl}_{4}$-induced injury and fibrogenesis (38). Moreover, our previous study demonstrated that Cur inhibited hypertension-induced cardiac fibrosis by activating PPAR- $\gamma$ (14). In this study, we found that treating VSMCs with AngII increased the expression of TNF- $\alpha$ and IL-6 and caused VSMC over-proliferation. This was accompanied by the suppression of PPAR- $\gamma$, which is consistent with previous studies. Treatment with Cur significantly attenuated AngII-induced expression of pro-inflammatory cytokines and VSMC proliferation by increasing PPAR- $\gamma$ expression and elevating its activation. Meanwhile, the PPAR- $\gamma$ antagonist GW9662 partially reversed the anti-inflammatory and antiproliferative effects of Cur in AngII-stimulated VSMCs by inhibiting PPAR- $\gamma$ activation. These results suggest that the activation of PPAR- $\gamma$, an inflammation-related nuclear transcription factor, is involved in the mechanism by which Cur suppresses AngII-induced inflammation and proliferation in VSMCs.

Growing evidence shows that oxidative stress, characterized by the overexpression of intercellular ROS, plays a critical role in the progression of atherosclerosis (15). The common risk factors for atherosclerosis such as hypercholesterolemia, hypertension, aging, smoking and diabetes can induce overproduction of intercellular ROS, not only in VSMCs but also in endothelial cells and adventitial cells (39). ROS production affects almost all of the processes of atherosclerosis, such as lipid overload, abnormal lipid metabolism, calcium-related signaling pathway inhibition, endoplasmic reticulum stress, VSMC proliferation and endothelial cell dysfunction (40). ROS cause direct cellular damage, but it can also act as potential secondary messengers that participate in the inflammatory response (5). Therefore, we believe that there is a close relationship between ROS production and inflammation. Some studies have shown that inhibition of ROS production may be an effective way to suppress atherosclerosis $(41,42)$. Growing evidence indicates that Cur may be a potential scavenger of intracellular ROS $(5,43,44)$. In our previous study, we found that Cur can inhibit NADPH-mediated iROS and free radical production in LPS-stimulated VSMCs (5). In the present study, we found that AngII significantly increased intracellular ROS production in VSMCs, which agrees with previous studies $(13,45)$. Treatment with Cur effectively attenuated the AngII-induced increase in intracellular ROS and inhibited free radical production by VSMCs. To detect whether the anti-inflammatory and anti-proliferative effects of Cur are linked with inhibition of ROS production, we pretreated the cells with DPI, a ROS antagonist. Our results indicated that this was accompanied by a decrease in ROS production, pro-inflammatory cytokine release and cell proliferation in AngII-stimulated VSMCs. These responses were further decreased when the cells were treated with a combination of Cur and DPI. These results indicate that targeting ROS may be a critical mechanism by which Cur induces its anti-inflammatory and anti-proliferative effects on AngII-stimulated VSMCs.

It is generally recognized that the membrane-associated enzyme NADPH oxidase is the main source of intracellular 
ROS production in mammal cells. At present, NADPH oxidase is expressed in almost all cell types of the cardiovascular system, including VSMCs, cardiac fibrosis, cardiomyocytes, and endothelial cells (16). Recent studies have focused on the relationship between NADPH oxidase activation and the progression of atherosclerosis $(18,46)$. p47phox is one of the three main subunits of the NADPH oxidase cytosolic component (16). Stimulation of cells causes an increase in p47phox expression and an elevation in intracellular ROS (47). Therefore it is generally recognized that detection of $\mathrm{p} 47 \mathrm{phox}$ expression is an effective way to determine NADPH oxidase activation. In vivo, a previous study revealed that impaired p47phox function significantly reduced atherosclerotic plaque area and attenuated plaque vulnerability caused by a highfat diet (compared with the $\mathrm{ApoE}^{-/-}$mice of normal p47phox function) (17). These previous studies suggest that inhibition of NADPH oxidase activation may be an effective way to suppress the progression of atherosclerosis. Moreover, studies have reported that the inhibitory effect of Cur on NADPH oxidase activation may play a critical role in its antioxidation by decreasing intracellular ROS production $(5,48,49)$. As shown by our results, the expression of $\mathrm{p} 47$ phox was significantly elevated after stimulation by AngII, and was accompanied by an increase in ROS production. Treatment with Cur effectively suppressed AngII-induced elevation of p47phox expression. These results revealed that the inhibitory effect of Cur on ROS production may be partially mediated by NADPH oxidase. It is worth mentioning that other pathways have also been observed to contribute to ROS production, such as the mitochondrial electron chain, and it is worthwhile to explore other signaling pathways that participate in the inhibitory effect of Cur on ROS production. It is possible that, in addition to NADPH oxidase, other pathways contribute to this effect in AngII-stimulated VSMCs.

In conclusion, the present study demonstrated that Cur attenuated AngII-induced production of TNF- $\alpha$, IL- 6 and NO, and cell proliferation in VMSCs. The anti-inflammatory and anti-proliferative effect of Cur may partially depend on an increase in PPAR- $\gamma$ activity and suppression of NADPH oxidase-mediated intracellular ROS production. These results may provide a novel mechanism to explain the pharmacological effect of Cur on chronic inflammation-related diseases, and its potentially beneficial effect on atherosclerosis.

\section{Acknowledgements}

This study was supported by the Youth Foundation of the First Affiliated Hospital of Zhengzhou University (YFFAHZZ 2013020105 to Z.M.).

\section{References}

1. Jiang G, Wang D, Li W, Pan Y, Zheng W, Zhang H and Sun YV: Coronary heart disease mortality in China: Age, gender, and urban-rural gaps during epidemiological transition. Rev Panam Salud Publica 31: 317-324, 2012.

2. Bäck M and Hansson GK: Anti-inflammatory therapies for atherosclerosis. Nat Rev Cardiol 12: 199-211, 2015.

3. Libby P: Inflammation in atherosclerosis. Arterioscler Thromb Vasc Biol 32: 2045-2051, 2012

4. Chistiakov DA, Orekhov AN and Bobryshev YV: Vascular smooth muscle cell in atherosclerosis. Acta Physiol (Oxf) 214 33-50, 2015.
5. Meng Z, Yan C, Deng Q, Gao DF and Niu XL: Curcumin inhibits LPS-induced inflammation in rat vascular smooth muscle cells in vitro via ROS-relative TLR4-MAPK/NF- $\kappa \mathrm{B}$ pathways. Acta Pharmacol Sin 34: 901-911, 2013.

6. Pacurari M, Kafoury R, Tchounwou PB and Ndebele K: The renin-angiotensin-aldosterone system in vascular inflammation and remodeling. Int J Inflam 2014: 689360, 2014.

7. Askari AT, Shishehbor MH, Kaminski MA, Riley MJ, Hsu A and Lincoff AM; GUSTO-V Investigators: The association between early ventricular arrhythmias, renin-angiotensin-aldosterone system antagonism, and mortality in patients with ST-segment-elevation myocardial infarction: insights from Global Use of Strategies to Open Coronary Arteries (GUSTO) V. Am Heart J 158: 238-243, 2009.

8. Derosa G and Maffioli P: Peroxisome proliferator-activated receptor- $\gamma($ PPAR- $\gamma)$ agonists on glycemic control, lipid profile and cardiovascular risk. Curr Mol Pharmacol 5: 272-281, 2012.

9. Usuda D and Kanda T: Peroxisome proliferator-activated receptors for hypertension. World J Cardiol 6: 744-754, 2014.

10. Fuentes E, Guzmán-Jofre L, Moore-Carrasco R and Palomo I: Role of PPARs in inflammatory processes associated with metabolic syndrome (Review). Mol Med Rep 8: 1611-1616, 2013.

11. Liu WX, Wang T, Zhou F, Wang Y, Xing JW, Zhang S, Gu SZ, Sang LX, Dai C and Wang HL: Voluntary exercise prevents colonic inflammation in high-fat diet-induced obese mice by up-regulating PPAR-gamma activity. Biochem Biophys Res Commun 459: 475-480, 2015.

12. Marchesi C, Rehman A, Rautureau Y, Kasal DA, Briet M, Leibowitz A, Simeone SM, Ebrahimian T, Neves MF, Offermanns S, et al: Protective role of vascular smooth muscle cell PPAR $\gamma$ in angiotensin II-induced vascular disease. Cardiovasc Res 97: 562-570, 2013.

13. Ji Y, Liu J, Wang Z, Liu N and Gou W: PPARgamma agonist, rosiglitazone, regulates angiotensin II-induced vascular inflammation through the TLR4-dependent signaling pathway. Lab Invest 89: 887-902, 2009.

14. Meng Z, Yu XH, Chen J, Li L and Li S: Curcumin attenuates cardiac fibrosis in spontaneously hypertensive rats through PPAR- $\gamma$ activation. Acta Pharmacol Sin 35: 1247-1256, 2014.

15. Li H, Horke S and Förstermann U: Vascular oxidative stress, nitric oxide and atherosclerosis. Atherosclerosis 237: 208-219, 2014.

16. Madamanchi NR and Runge MS: NADPH oxidases and atherosclerosis: Unraveling the details. Am J Physiol Heart Circ Physiol 298: H1-H2, 2010.

17. Barry-Lane PA, Patterson C, van der Merwe M, Hu Z, Holland SM, Yeh ET and Runge MS: p47phox is required for atherosclerotic lesion progression in $\mathrm{ApoE}(-/-)$ mice. J Clin Invest 108: 1513-1522, 2001.

18. Kinkade K, Streeter J and Miller FJ: Inhibition of NADPH oxidase by apocynin attenuates progression of atherosclerosis. Int J Mol Sci 14: 17017-17028, 2013.

19. Goel A, Kunnumakkara AB and Aggarwal BB: Curcumin as 'Curecumin': From kitchen to clinic. Biochem Pharmacol 75: 787-809, 2008.

20. Barzegar A and Moosavi-Movahedi AA: Intracellular ROS protection efficiency and free radical-scavenging activity of curcumin. PLoS One 6: e26012, 2011.

21. Feng HL, Fan H, Dang HZ, Chen XP, Ren Y, Yang JD and Wang PW: Neuroprotective effect of curcumin to $A \beta$ of double transgenic mice with Alzheimer's disease. Zhongguo Zhong Yao Za Zhi 39: 3846-3849, 2014 (In Chinese).

22. Sahebkar A: Dual effect of curcumin in preventing atherosclerosis: The potential role of pro-oxidant-antioxidant mechanisms. Nat Prod Res 29: 491-492, 2015.

23. Griendling KK, Taubman MB, Akers M, Mendlowitz M and Alexander RW: Characterization of phosphatidylinositol-specific phospholipase $\mathrm{C}$ from cultured vascular smooth muscle cells. J Biol Chem 266: 15498-15504, 1991.

24. Van Hoogmoed LM, Snyder JR and Harmon F: In vitro investigation of the effect of prostaglandins and nonsteroidal anti-inflammatory drugs on contractile activity of the equine smooth muscle of the dorsal colon, ventral colon, and pelvic flexure. Am J Vet Res 61: 1259-1266, 2000.

25. Jeong JM, Choi CH, Kang SK, Lee IH, Lee JY and Jung H: Antioxidant and chemosensitizing effects of flavonoids with hydroxy and/or methoxy groups and structure-activity relationship. J Pharm Pharm Sci 10: 537-546, 2007.

26. Mehta JL and Romeo F: Inflammation, infection and atherosclerosis: Do antibacterials have a role in the therapy of coronary artery disease? Drugs 59: 159-170, 2000. 
27. Peters S: Inhibition of atherosclerosis by angiotensin II type 1 receptor antagonists. Am J Cardiovasc Drugs 13: 221-224, 2013.

28. Durante A, Peretto G, Laricchia A, Ancona F, Spartera M, Mangieri A and Cianflone D: Role of the renin-angiotensinaldosterone system in the pathogenesis of atherosclerosis. Curr Pharm Des 18: 981-1004, 2012.

29. Fu Z, Wang M, Gucek M, Zhang J, Wu J, Jiang L, Monticone RE, Khazan B, Telljohann R, Mattison J, et al: Milk fat globule protein epidermal growth factor-8: A pivotal relay element within the angiotensin II and monocyte chemoattractant protein-1 signaling cascade mediating vascular smooth muscle cells invasion. Circ Res 104: 1337-1346, 2009.

30. Kawashima S: The two faces of endothelial nitric oxide synthase in the pathophysiology of atherosclerosis. Endothelium 11: 99-107, 2004.

31. Bunderson M, Coffin JD and Beall HD: Arsenic induces peroxynitrite generation and cyclooxygenase- 2 protein expression in aortic endothelial cells: Possible role in atherosclerosis. Toxicol Appl Pharmacol 184: 11-18, 2002.

32. Detmers PA, Hernandez M, Mudgett J, Hassing H, Burton C, Mundt S, Chun S, Fletcher D, Card DJ, Lisnock J, et al: Deficiency in inducible nitric oxide synthase results in reduced atherosclerosis in apolipoprotein E-deficient mice. J Immunol 165 3430-3435, 2000.

33. Grygiel-Górniak B: Peroxisome proliferator-activated receptors and their ligands: Nutritional and clinical implications - a review. Nutr J 13: 17, 2014.

34. Azhar S: Peroxisome proliferator-activated receptors, metabolic syndrome and cardiovascular disease. Future Cardiol 6: 657-691, 2010.

35. Matsumura T, Kinoshita H, Ishii N, Fukuda K, Motoshima H, Senokuchi T, Taketa K, Kawasaki S, Nishimaki-Mogami T, Kawada T, et al: Telmisartan exerts antiatherosclerotic effects by activating peroxisome proliferator-activated receptor- $\gamma$ in macrophages. Arterioscler Thromb Vasc Biol 31: 1268-1275, 2011.

36. Siddiqui AM, Cui X, Wu R, Dong W, Zhou M, Hu M, Simms HH and Wang P: The anti-inflammatory effect of curcumin in an experimental model of sepsis is mediated by up-regulation of peroxisome proliferator-activated receptor-gamma. Crit Care Med 34: 1874-1882, 2006.

37. Ghosh SS, Massey HD, Krieg R, Fazelbhoy ZA, Ghosh S, Sica DA, Fakhry I and Gehr TW: Curcumin ameliorates renal failure in 5/6 nephrectomized rats: Role of inflammation. Am J Physiol Renal Physiol 296: F1146-F1157, 2009.

38. Fu Y, Zheng S, Lin J, Ryerse J and Chen A: Curcumin protects the rat liver from $\mathrm{CCl}_{4}$-caused injury and fibrogenesis by attenuating oxidative stress and suppressing inflammation. Mol Pharmacol 73: 399-409, 2008
39. Tousoulis D, Psaltopoulou T, Androulakis E, Papageorgiou N, Papaioannou S, Oikonomou E, Synetos A and Stefanadis C: Oxidative stress and early atherosclerosis: Novel antioxidant treatment. Cardiovasc Drugs Ther 29: 75-88, 2015.

40. Li H, Horke S and Förstermann U: Oxidative stress in vascular disease and its pharmacological prevention. Trends Pharmacol Sci 34: 313-319, 2013.

41. Sun GB, Qin M, Ye JX, Pan RL, Meng XB, Wang M, Luo Y, Li ZY, Wang HW and Sun XB: Inhibitory effects of myricitrin on oxidative stress-induced endothelial damage and early atherosclerosis in $\mathrm{ApoE}^{-/}$mice. Toxicol Appl Pharmacol 271: 114-126, 2013.

42. Hort MA, Straliotto MR, Netto PM, da Rocha JB, de Bem AF and Ribeiro-do-Valle RM: Diphenyl diselenide effectively reduces atherosclerotic lesions in $\mathrm{LDLr}^{-1-}$ mice by attenuation of oxidative stress and inflammation. J Cardiovasc Pharmacol 58: 91-101, 2011.

43. Rong S, Zhao Y, Bao W, Xiao X, Wang D, Nussler AK, Yan H, Yao P and Liu L: Curcumin prevents chronic alcohol-induced liver disease involving decreasing ROS generation and enhancing antioxidative capacity. Phytomedicine 19: 545-550, 2012.

44. Yu W, Wu J, Cai F, Xiang J, Zha W, Fan D, Guo S, Ming Z and Liu C: Curcumin alleviates diabetic cardiomyopathy in experimental diabetic rats. PLoS One 7: e52013, 2012.

45. Bruder-Nascimento T, Chinnasamy P, Riascos-Bernal DF, Cau SB, Callera GE, Touyz RM, Tostes RC and Sibinga NE: Angiotensin II induces Fat1 expression/activation and vascular smooth muscle cell migration via Nox1-dependent reactive oxygen species generation. J Mol Cell Cardiol 66: 18-26, 2014.

46. Gray SP, Di Marco E, Okabe J, Szyndralewiez C, Heitz F, Montezano AC, de Haan JB, Koulis C, El-Osta A, Andrews KL, et al: NADPH oxidase 1 plays a key role in diabetes mellitusaccelerated atherosclerosis. Circulation 127: 1888-1902, 2013.

47. Ushio-Fukai M: Localizing NADPH oxidase-derived ROS. Sci STKE 2006: re8, 2006.

48. Zhao WC, Zhang B, Liao MJ, Zhang WX, He WY, Wang HB and Yang CX: Curcumin ameliorated diabetic neuropathy partially by inhibition of NADPH oxidase mediating oxidative stress in the spinal cord. Neurosci Lett 560: 81-85, 2014

49. Derochette S, Franck T, Mouithys-Mickalad A, Ceusters J, Deby-Dupont G, Lejeune JP, Neven P and Serteyn D: Curcumin and resveratrol act by different ways on NADPH oxidase activity and reactive oxygen species produced by equine neutrophils. Chem Biol Interact 206: 186-193, 2013. 